\title{
Clinical guide SEOM on venous thromboembolism in cancer patients
}

\author{
A. J. Muñoz Martín · C. Font Puig • \\ L. M. Navarro Martín · P. Borrega García · \\ M. Martín Jiménez
}

Received: 24 September 2014/ Accepted: 26 September 2014/Published online: 1 November 2014

(C) The Author(s) 2014. This article is published with open access at Springerlink.com

\begin{abstract}
Venous thromboembolism (VTE) is a common event in cancer patients and one of the major causes of cancer-associated mortality and a leading cause of morbidity. In recent years, the incidence rates of VTE have notably increased; however, VTE is still commonly underestimated by oncologists. VTE is considered an adverse prognostic factor in cancer patients in all settings. In 2011 the Spanish Society of Medical Oncology (SEOM) first published a clinical guideline of prophylaxis and treatment of VTE in cancer patients. In an effort to incorporate evidence obtained since the original publication, SEOM presents an update of the guideline for thrombosis and cancer in order to improve the prevention and management of VTE.
\end{abstract}

Keywords Cancer - Thrombosis - Guidelines · Anticoagulation

A. J. Muñoz Martín $(\varangle) \cdot$ M. Martín Jiménez

Medical Oncology Service, Gregorio Marañón University

General Hospital, Madrid, Spain

e-mail: andresmunmar@hotmail.com

C. Font Puig

Servicio de Oncología Médica-Hospital de Día, Hospital Clinic i

Provincial, Barcelona, Spain

L. M. Navarro Martín

Medical Oncology Service, University Hospital of Salamanca,

Salamanca, Spain

P. Borrega García

Medical Oncology Service, Cáceres Hospital Complex,

Cáceres, Spain

\section{Introduction}

Venous thromboembolism (VTE) is a significant cause of morbidity and death in patients with cancer. Although deep vein thrombosis (DVT) of limbs and pulmonary embolism (PE) are the most commonly encountered venous thrombotic complications, other vascular territories, such as the splanchnic veins and central nervous system can be involved. The risk of VTE is estimated to be fourfold higher in cancer patients compared with non-cancer patients. The true incidence of VTE in cancer patients remains uncertain, with reported incidence rates ranging from $0.8 \%$ to over $30 \%$ in some populations, and depends on several factors (tumor, host and treatment-related factors) [1]. VTE is often asymptomatic or minimally symptomatic, therefore the incidence is likely to be much higher. A steady increase in the incidence of cancer-associated thrombosis (CAT) has been observed in the past two decades due to multiple factors: increasing age of general population and cancer prevalence, improved imaging techniques with enhanced detection of incidental thrombosis and greater thrombogenicity of current multiagent chemotherapy regimens. Cancer patients with VTE have an increased incidence of VTE recurrence and anticoagulant-related bleeding complications compared with patients without cancer. VTE has been found to be an adverse prognosis factor in all stages of cancer [2]. In the last decade it was postulated that the aggressiveness of a malignant tumor is clearly correlated to the incidence of VTE.

Here, we review the prophylaxis and treatment of VTE in cancer patients using the GRADE system for all the recommendations $[3,4]$. 


\section{Risk factors}

The risk of VTE varies notably between cancer patients, even in the same patient over the course of the disease. Risk factors for CAT can be divided into three categories: patient-, treatment- and cancer- related factors (Table 1).

\section{Prophylaxis}

Prophylaxis of VTE in hospitalized medical cancer patients

Hospitalization is one of the main VTE risk factors with surgery and trauma. Medical hospitalized patients are at significant risk of developing VTE and thromboprophylaxis has been shown to be effective in three large randomized phase III trials [5-7]. All three studies reported a significant reduction in VTE following treatment with low-molecular-weight heparins (LMWH) or fondaparinux, compared with placebo. However, there is a lack of evidence regarding hospitalized cancer patients, because no specific trials have ever been conducted in the cancer population. The only evidence available is the subgroup analysis of the aforementioned trials (Table 2). LMWH trials showed similar VTE reductions; however, an increase incidence of VTE paradoxically was observed with fondaparinux. Major bleeding rates were not reported in the three placebo-controlled trials. A recent meta-analysis [8] of the cancer population in these three studies showed that cancer patients did not gain a significant reduction in the incidence of VTE when pharmacological anticoagulation was used. Different explanations have been suggested for this finding as lack of statistical power, small number of patients included in the analysis (307 patients), lack of stratification according to VTE risk or cancer status, heterogeneity between studies, lack of efficacy using standard doses of drug prophylaxis (higher doses in this high-risk population) or low-risk patients included in these trials. Finally, it has been suggested that fondaparinux is less efficacious than LMWH.

Some observational studies suggest that VTE risk in cancer patients extends beyond their hospital stay; however, there is no evidence to recommend extended thromboprophylaxis after discharge. No specific trials have been performed with the new oral anticoagulants (NOACS) in this setting in cancer patients. To date there is a lack of validated risk assessment tools for estimating the overall risk of VTE and bleeding in hospitalized cancer patients. Identifying patients who could benefit most from pharmacologic prophylaxis and performing targeted thromboprophylaxis are important issues for specialists caring for cancer patients.
Table 1 Risk factors for VTE

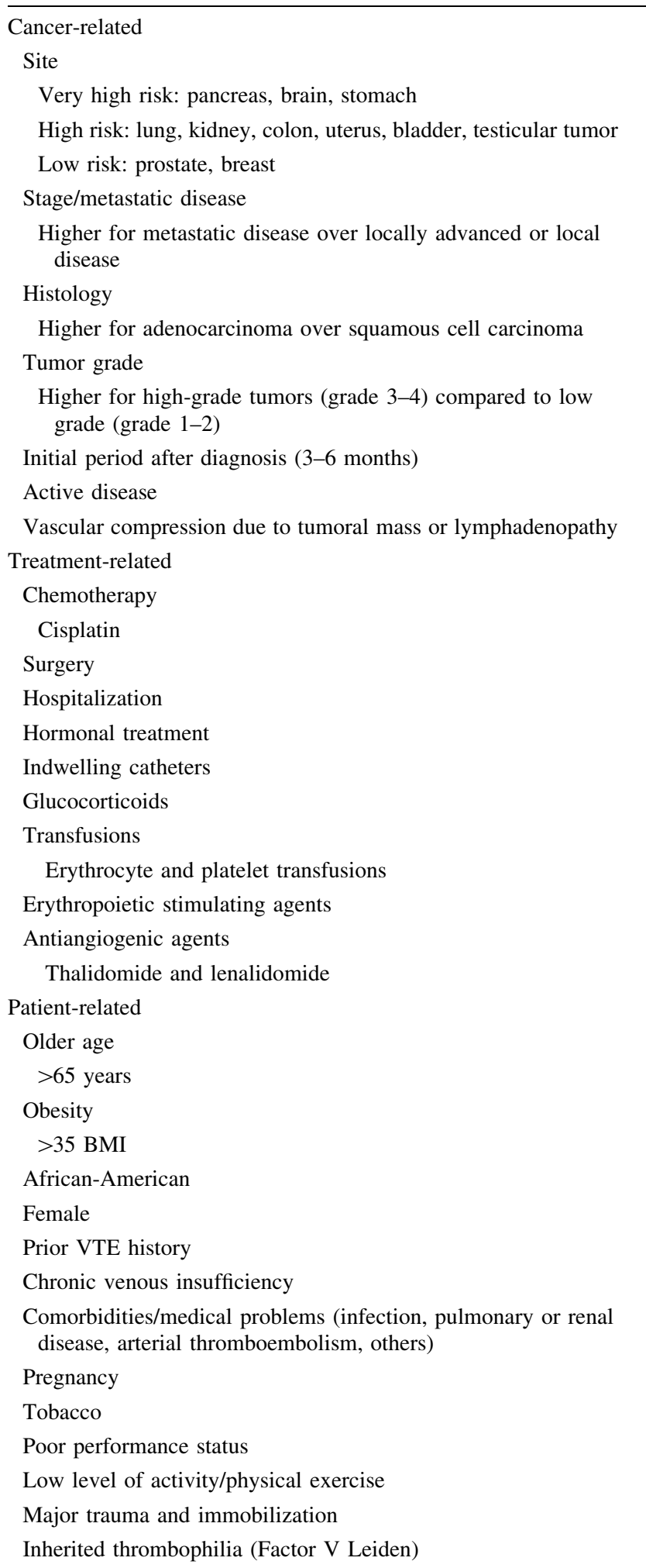

$B M I$ body mass index 
Table 2 Clinical trials assessing prophylaxis of VTE in hospitalized medical patients

\begin{tabular}{|c|c|c|c|c|c|c|c|c|}
\hline Clinical trial & $\begin{array}{l}\text { Number } \\
\text { of patients }\end{array}$ & $\begin{array}{l}\text { Cancer } \\
\text { patients } \\
(\%)\end{array}$ & Study drugs & VTE events & $\begin{array}{l}\text { Relative } \\
\text { risk } \\
\text { reduction }\end{array}$ & $\begin{array}{l}\text { Major } \\
\text { bleeding }\end{array}$ & NTT & $\begin{array}{l}\text { Cancer subgroup } \\
\text { VTE events }\end{array}$ \\
\hline ARTEMIS & 849 & 15.4 & $\begin{array}{l}\text { Fondaparinux sc } \\
(2.5 \mathrm{mg} / 24 \mathrm{~h}) \mathrm{vs} . \\
\text { placebo }\end{array}$ & $\begin{array}{c}5.6 \text { vs. } 10.5 \% \\
p=0.029\end{array}$ & 0.47 & $\begin{array}{l}0.2 \text { vs. } 0.2 \% \\
p=\mathrm{NS}\end{array}$ & 20 & $\begin{array}{l}17.0 \text { vs. } 3.9 \% \text { RR } 4.3 \\
\text { NNH } 8\end{array}$ \\
\hline MEDENOX & 866 & 12.4 & $\begin{array}{l}\text { Enoxaparin sc } \\
(40 \mathrm{mg} / 24 \mathrm{~h}) \mathrm{vs} . \\
\text { placebo }\end{array}$ & $\begin{array}{c}5.5 \text { vs. } 14.9 \% \\
p<0.001\end{array}$ & 0.37 & $\begin{array}{c}1.7 \text { vs. } 1.1 \% \\
p=\mathrm{NS}\end{array}$ & 11 & $\begin{array}{l}9.7 \text { vs. } 19.5 \% \text { RR } 0.50 \\
(95 \% \text { CI } 0.14-1.72) \\
\text { NNT } 10\end{array}$ \\
\hline PREVENT & 3,706 & 5.1 & $\begin{array}{l}\text { Dalteparin sc } \\
(5,000 \mathrm{UI} / 24 \mathrm{~h}) \mathrm{vs} . \\
\text { placebo }\end{array}$ & $\begin{array}{r}2.8 \text { vs. } 5.0 \% \\
p=0.0015\end{array}$ & 0.55 & $\begin{array}{l}0.5 \text { vs. } 0.2 \% \\
p=\mathrm{NS}\end{array}$ & 45 & $\begin{array}{l}3.1 \text { vs. } 8.3 \% \text { RR } 0.37 \\
\text { NNT } 18\end{array}$ \\
\hline
\end{tabular}

sc subcutaneously, VTE venous thromboembolism, $N S$ not significant, $N T T$ number of patients needed to treat to avoid one event, $N N H$ number needed to harm, $R R$ relative risk, $C I$ confidence interval

\section{Recommendation}

Despite the paucity of data, prophylactic anticoagulation should be considered for hospitalized cancer patients with acute medical illness in the absence of contraindications. The preferred agents are LMWH (level of evidence: grade 1B). There is no evidence to recommend NOACS or extended prophylaxis after hospital discharge.

\section{Prophylaxis of VTE in surgical cancer patients}

VTE is a common complication in cancer patients undergoing surgery. Cancer surgery doubles the risk of DVT and the risk of fatal postoperative $\mathrm{PE}$ is four times higher compared to similar procedures in the non-cancer population. In addition, cancer surgery is associated with an increased risk of bleeding. Several randomized studies and meta-analyses have demonstrated the benefit of pharmacologic prophylaxis in this setting with LMWH and UFH over no prophylaxis or placebo. Pharmacologic prophylaxis is ideally started before surgery or as soon as possible in the postoperative period. Multiple trials in unselected populations including cancer and non-cancer patients suggest LMWH and UFH are equally effective. Due to similar efficacy and unfavorable schedule (three times a day vs. once a day), LMWH is preferable to UFH in surgical cancer patients. There is a lack of data of the superiority of one type of LMWH over another. Classically prophylaxis is continued for at least 7-10 days. It must be noted $40 \%$ of the VTE events may occur later than 21 days from surgical intervention [9]. Prolonged prophylaxis for up to 4 weeks must be considered in patients undergoing major abdominal or pelvic surgery for cancer with additional risk factors (Table 1) [10]. Mechanical methods of thromboprophylaxis in monotherapy modestly reduce the frequency of VTE in cancer patients. Few data are available from prospective, randomized, controlled trials on their efficacy in cancer patients. Pharmacological thromboprophylaxis is superior to mechanical thromboprophylaxis in preventing VTE [11]. So mechanical methods are commonly used as an adjunct to pharmacological thromboprophylaxis. A very important advantage of mechanical methods is they are not associated to an increased risk of bleeding. The optimal prophylaxis for laparoscopic surgery or minimally invasive procedures has not been established and the real incidence of VTE is not well known. The need for pneumoperitoneum and reverse Trendelenburg position during laparoscopic procedure may increase the incidence of VTE in these patients. Observational studies reported laparoscopic surgery was associated with a lower incidence of VTE compared to open surgery. A recent Italian study published in 2013 showed the superiority of extended prophylaxis for 4 weeks over short prophylaxis (1 week) in patients who underwent laparoscopic surgery for colorectal cancer.

\section{Recommendation}

In the absence of contraindications, all patients undergoing major surgical intervention should receive pharmacologic thromboprophylaxis (level of evidence: grade 1A). The preferred agents are LMWH and prophylaxis should be started before surgery or as soon as possible in the postoperative period. Mechanical methods may be added to pharmacologic prophylaxis in high-risk patients but should not be used as monotherapy, unless pharmacologic prophylaxis is contraindicated (level of evidence: grade 2C). Patients should receive at least 7-10 days of prophylaxis and patients undergoing major abdominal or pelvic cancer surgery with high-risk features should be considered for extended thromboprophylaxis for 4 weeks (level of evidence: grade $1 \mathrm{~A})$.

We suggest the same recommendations for laparoscopic surgery, risk factors and the duration and type of the procedure must be assessed (level of evidence: grade 2C). 
Table 3 Prophylaxis of VTE in ambulatory cancer patients during chemotherapy: recentclinical trials and meta-analysis

\begin{tabular}{|c|c|c|c|c|c|c|c|c|}
\hline Study & $\begin{array}{l}\text { Number } \\
\text { of patients }\end{array}$ & Type of tumor & \multicolumn{2}{|c|}{ Risk of thrombosis } & \multicolumn{2}{|c|}{ LMWH } & \multicolumn{2}{|l|}{ Dose } \\
\hline $\begin{array}{l}\text { PROTECHT } \\
\text { Lancet Onc'09 }\end{array}$ & 1,150 & $\begin{array}{l}\text { Lung, pancreas, stomach, } \\
\text { colorectal, breast, } \\
\text { ovarian, head and neck } \\
\text { cancer }\end{array}$ & \multicolumn{2}{|c|}{$\begin{array}{l}\text { High (pancreas, stomach) } \\
\text { Low (breast, head and neck) }\end{array}$} & \multicolumn{2}{|c|}{ Nadroparin } & \multicolumn{2}{|l|}{$3,800 \mathrm{UI} / 24 \mathrm{~h}$} \\
\hline $\begin{array}{l}\text { FRAGEM UK } \\
\text { EJC'11 }\end{array}$ & 123 & Pancreas & \multicolumn{2}{|l|}{ High } & \multicolumn{2}{|c|}{ Dalteparin } & \multicolumn{2}{|c|}{$\begin{array}{l}200 \mathrm{UI} / \mathrm{kg} / 24 \mathrm{~h} \times 4 \text { weeks } \\
\text { followed } 150 \mathrm{UI} / \mathrm{kg} / \\
24 \mathrm{~h} \times 8 \text { weeks }\end{array}$} \\
\hline $\begin{array}{l}\text { CONKO } 004 \\
\text { ASCO' } 10\end{array}$ & 312 & Pancreas & \multicolumn{2}{|l|}{ High } & \multicolumn{2}{|c|}{ Enoxaparin } & \multicolumn{2}{|c|}{$\begin{array}{l}1 \mathrm{mg} / \mathrm{kg} / 24 \mathrm{~h} \times 3 \mathrm{~m}, \\
\text { followed } \\
40 \mathrm{mg} / 24 \mathrm{~h} \times 3 \mathrm{~m}\end{array}$} \\
\hline $\begin{array}{l}\text { SAVE ONCO } \\
\text { NEJM'12 }\end{array}$ & 3,212 & $\begin{array}{l}\text { Lung, colorectal, stomach, } \\
\text { pancreas, kidney and } \\
\text { ovarian cancer }\end{array}$ & \multicolumn{2}{|c|}{ Moderate-high } & \multicolumn{2}{|c|}{ Semuloparin } & \multicolumn{2}{|l|}{$20 \mathrm{mg} / 24 \mathrm{~h}$} \\
\hline $\begin{array}{l}\text { Meta-analysis } \\
\text { Cochrane } 2012\end{array}$ & 3,538 & Multiple neoplasms & \multicolumn{2}{|l|}{ Not defined } & - & & \multicolumn{2}{|l|}{-} \\
\hline $\begin{array}{l}\text { Akl pooled analysis } \\
\text { NEJM' } 12\end{array}$ & $\approx 6.000$ & Multiple neoplasms & \multicolumn{2}{|l|}{ Not defined } & - & & \multicolumn{2}{|l|}{-} \\
\hline \multicolumn{2}{|l|}{ Duration } & \multicolumn{2}{|c|}{ VTE (\%) CT + LMWH vs. CT } & \multicolumn{2}{|c|}{$\begin{array}{l}\text { Major bleeding CT } \\
+ \text { LMWH vs. QT }\end{array}$} & \multicolumn{2}{|c|}{$\begin{array}{l}\text { Minor bleeding CT } \\
+ \text { LMWH vs. CT }\end{array}$} & NNT \\
\hline \multicolumn{2}{|l|}{4 months } & \multicolumn{2}{|c|}{2.0 vs. $3.9 \% *(\mathrm{VTE}+\mathrm{ATE}) p=0.02$} & \multicolumn{2}{|c|}{0.7 vs. $0 \% p=0.18$} & \multicolumn{2}{|c|}{7.4 vs. $7.9 \%$} & 53 \\
\hline \multicolumn{2}{|l|}{12 weeks } & \multicolumn{2}{|c|}{3.4 vs. $23.0 \%$ RR $0.145, p=0.002$} & \multicolumn{2}{|l|}{3.4 vs. $3.2 \%$} & \multicolumn{2}{|c|}{9.0 vs. $3.0 \%$} & - \\
\hline \multicolumn{2}{|l|}{6 months } & \multicolumn{2}{|l|}{5.1 vs. $15.6 \% p<0.05$} & \multicolumn{2}{|c|}{ No difference $p=\mathrm{NS}$} & \multicolumn{2}{|l|}{ NR } & 12 (sVTE) \\
\hline \multicolumn{2}{|c|}{ Until a change of $\mathrm{CT}$ regimen } & \multicolumn{2}{|c|}{$1.2 \%$ vs. $3.4 \%$ HR $0.36, p<0.001$} & 1.2 vs. $1.2 \%$ & & $1.6 v$ & vs. $0.9 \%$ & 46 \\
\hline- & & Heparin vs. no prophylaxis & & & & & & 60 (sVTE) \\
\hline & & $0.55(0.34-0.88)$ & & $1.57(0.69-3.60$ & & - & & \\
\hline- & & Heparin vs. no prophylaxis & & & & & & - \\
\hline & & $0.57(0.40-0.81)$ & & $1.06(0.71-1.57$ & & 1.18 & $(0.89-1.55)$ & \\
\hline
\end{tabular}

$m$ months, $m g$ milligram, $C T$ chemotherapy, $N N T$ number of patients needed to treat to avoid one event, $s V T E$ symptomatic venous thromboembolism, $N S$ not significant, $H R$ hazard ratio

* Venous thromboembolism incidence plus arterial thormboembolism incidence

Prophylaxis of VTE in ambulatory cancer patients during chemotherapy

Chemotherapy has been identified as an independent risk factor for VTE. The rates of thrombosis in ambulatory patients receiving chemotherapy vary widely and depend on multiple factors (see Table 1). Several randomized trials evaluating ambulatory prophylaxis with LMWH and lowdose warfarin in ambulatory cancer patients have been published with inconsistent results largely due to the heterogeneity of the populations studied and the treatments used (duration, drugs, dose, etc.). Since 2009 four randomized trials [12-15] and three meta-analyses [16-18] have been published and have changed the landscape of thromboprophylaxis in this setting (Table 3). All studies randomized patients with cancer receiving chemotherapy to venous thromboprophylaxis or placebo. These studies consistently demonstrate the benefit of thromboprophylaxis in different types of malignancies with a significant reduced risk of VTE with an acceptable safety profile. However, the overall rates of VTE among patients assigned to placebo were very low, ranging 3-4\% in the multitumor trials which is lower than observed in the real world $[12,13]$. The lower VTE incidence rates have been suggested by the inclusion of selected low-risk patients. Therefore, despite a consistent and robust reduction in the risk of VTE with a hazard ratio under 0.4 in these studies, the difference in absolute risk is small. The rate of major and minor bleeding was similar between the two arms. Even though there was a decrease in the VTE incidence no difference in overall survival was observed. The effect of this type of thromboprophylaxis on quality of life has not been assessed. According to the evidence from these trials and Cochrane meta-analysis the number of patients needed to treat to avoid one VTE event (NNT) would range between 46 and 60 . In consequence, all these issues and the cost of LMWH have limited the expansion of thromboprophylaxis in the ambulatory setting. A pooled analysis 
[18] that included more than 6,000 patients showed a significant reduction in symptomatic VTE (relative risk 0.57 , $95 \%$ CI 0.40-0.81) and a non-significant effect on major or minor bleeding (Table 3). This analysis also suggested a small survival benefit for prophylaxis with LMWH (relative risk 0.94, $95 \%$ CI 0.88-1.00) not observed in the previous studies [18].

The risk of VTE in patients diagnosed with multiple myeloma receiving treatment with thalidomide or lenalidomide plus chemotherapy or dexamethasone ranges from 12 to $28 \%$. When any pharmacologic thromboprophylaxis strategy is scheduled, this figure drops below $10 \%$. There is a lack of randomized studies in patients with multiple myeloma treated with thalidomide or lenalidomide in combination with chemotherapy or dexamethasone comparing VTE prophylaxis vs. observation. Two randomized controlled trials that compared different strategies of prophylaxis have been published [19, 20]. They showed aspirin and LMWH are acceptable thromboprophylaxis options and both suggested slightly greater efficacy of LMWH compared with aspirin.

It is important to identify patients at higher risk for whom prophylaxis may be beneficial. A validated risk assessment model (RAM) for identifying patients at high risk for VTE receiving chemotherapy has been validated by Khorana et al. [21]. Five predictive variables were identified and three different risk categories were defined (Table 4). This RAM is also highly predictive of mortality and progression-free survival. Recently, this model has been expanded with the addition of D-dimer and P-selectin. The addition of these biomarkers improves the risk prediction of VTE considerably; nevertheless, this expanded model has little impact since P-selectin is not available in clinical practice and has not been validated. In the near future new biomarkers may enhance the VTE prediction in this setting.

\section{Recommendation}

Routine thromboprophylaxis is not recommended in ambulatory cancer patients receiving chemotherapy (level of evidence: grade 1B). LMWH may be considered in highrisk ambulatory cancer patients, as advanced pancreatic cancer or patients with a Khorana score $\geq 3$, with low bleeding risk. Ambulatory patients who are receiving chemotherapy and prophylaxis with LMWH against VTE should be closely monitored.

It is recommended to assess the risk of VTE in all patients starting chemotherapy. Khorana's score is the only validated RAM in cancer patients receiving chemotherapy and is the recommended tool to assess VTE risk. Risk assessments should be performed periodically throughout the patient's chemotherapy (level of evidence: grade 2C).
Table 4 Khorana's risk assessment model (RAM)

\begin{tabular}{|c|c|c|c|}
\hline \multicolumn{3}{|l|}{ Patient characteristics } & Risk score points \\
\hline \multicolumn{4}{|l|}{ Site of cancer } \\
\hline \multicolumn{3}{|c|}{ Very high risk (stomach, pancreas) } & 2 \\
\hline \multicolumn{3}{|c|}{$\begin{array}{l}\text { High risk (lung, lymphoma, gynecologic, } \\
\text { genitourinary excluding prostate) }\end{array}$} & 1 \\
\hline \multicolumn{3}{|c|}{ Pre-chemotherapy platelet count $\geq 350,000 / \mathrm{mm}^{3}$} & 1 \\
\hline \multicolumn{3}{|c|}{$\begin{array}{l}\text { Hemoglobin level less than }<10 \mathrm{~g} / \mathrm{dl} \text { or use of red } \\
\text { cell growth factors }\end{array}$} & 1 \\
\hline \multicolumn{3}{|c|}{ Pre-chemotherapy leukocyte count $>11,000 / \mathrm{mm}^{3}$} & 1 \\
\hline \multicolumn{3}{|l|}{ BMI $35 \geq 35 \mathrm{~kg} / \mathrm{m}^{2}$} & 1 \\
\hline Risk score (points) & Risk category & \multicolumn{2}{|c|}{$\begin{array}{l}\text { Rates of sVTE according } \\
\text { to scores }(\%)\end{array}$} \\
\hline 0 & Low & \multicolumn{2}{|l|}{$0.3-0.8$} \\
\hline $1-2$ & Intermediate & \multicolumn{2}{|l|}{$1.8-2.0$} \\
\hline$\geq 3$ & High & \multicolumn{2}{|l|}{$6.7-7.1$} \\
\hline
\end{tabular}

BMI body mass index, sVTE symptomatic VTE

Pharmacologic thromboprophylaxis is recommended in patients diagnosed with multiple myeloma receiving treatment with thalidomide or lenalidomide plus chemotherapy or dexamethasone. LMWH is recommended for high-risk patients and aspirin for low-risk patients (level of evidence: grade $2 \mathrm{~B}$ ).

Prophylaxis of VTE in cancer patients with central venous catheters

Central venous catheters (CVC) are associated with upper extremity DVT and PE and are considered independent risk factors for VTE. Controversy remains regarding the true incidence of the disease, as many CVC-associated VTEs remain subclinical. The latest data suggest that while CVC-associated symptomatic VTE incidence only amounts to 2-5 \%, asymptomatic VTE may be as high as 27-66 \%, depending on the screening method used. In recent years a reduction of the CVCassociated VTE rate has been described. This finding is likely to be due to the introduction of less thrombogenic materials in the manufacturing of CVC. The most recent and largest studies and a meta-analysis of randomized trials did not show clinically meaningful degrees of protection against catheter-induced upper extremity venous thrombosis using either low-dose warfarin or LMWH in patients with cancer. Several studies including one meta-analysis [22] have suggested that CVC should be placed on the right side, in the jugular vein and the catheter tip should be positioned at the right atrium/ superior vena cava junction. 


\section{Recommendation}

Routine prophylaxis of VTE in cancer patients with CVC is not recommended. To reduce the incidence of VTE, CVC should be placed on the right side, in the jugular vein and the catheter tip should be positioned at the right atrium/ superior vena cava junction (level of evidence: grade 1A).

\section{Treatment}

The goals of anticoagulant therapy in cancer patients with CAT are to improve symptoms, reduce risk of recurrent VTE and decrease the risk of post-thrombotic syndrome (PTS). Anticoagulation is the cornerstone of treatment. Cancer patients present a higher risk of recurrent VTE and anticoagulant treatment-related bleeding compared to those without malignancy during anticoagulation therapy [23].

Initial treatment of VTE in cancer patients (5-10 days)

There are no randomized trials to specifically assess the initial treatment of VTE in cancer patients. Available clinical evidence comes from subgroup analysis and a meta-analysis of 16 randomized studies developed in the general population [24]. These studies neither found no significant differences in the VTE recurrence rate between LMWH and UFH nor the incidence of bleeding. However, a significant reduction in mortality at 3 months in favor of LMWH compared with UFH (RR 0.71 CI $95 \%$ 0.52-0.98) was shown. Initial treatment (5-10 days) of CAT with LMWH at a body weight-adjusted dose has become the drug of choice. LMWH administered subcutaneously is at least as safe and effective as UFH administered intravenously and LMWH usually requires no laboratory monitoring. Moreover, LMWH is associated with a reduced risk of developing heparin-induced thrombocytopenia (HIT) and osteoporosis compared to UFH. Alternative agents are UFH and fondaparinux according to the patient's characteristics and clinical situation. Fondaparinux is similar to LMWH in terms of administration route, efficacy, costs and convenience, but available data from randomized trials about this drug in cancer patients are scarce, so its use must be restricted to avoid HIT and previous allergic reactions to heparins.

Due to the lack of data in cancer populations, the indications and contraindications for the initial use of thrombolytic therapy are essentially the same as for non-cancer patients. The indications and potential benefits must be carefully weighed against the risk of adverse effects for each patient, due to the higher risk of major and fatal bleeding. Generally, it is only advisable in the management of patients with life- or limb-threatening thrombotic events. Multiple thrombolytic agents and regimens have been used, but any superiority of a particular agent or regimen remains to be definitively established.

\section{Recommendation}

LMWH at a body weight-adjusted dose is the drug of choice for the initial treatment of CAT (level of evidence: grade 1A). Thrombolytic therapy is only recommended in patients with life- or limb-threatening thrombotic events (level of evidence: grade $2 \mathrm{C}$ ).

Treatment of central venous catheter-associated thrombosis (CVCAT)

The cornerstone of the treatment of CVCAT is anticoagulant therapy and anticoagulation without CVC removal is the preferred approach in this setting. The type, duration and intensity of anticoagulant therapy of upper extremity deep vein thrombosis (UEDVT) should be the same as in the strategy employed for DVT of the legs. It is recommended to remove the CVC if $[25,26]$ : the catheter is not functional or the catheter is no longer needed, failure of anticoagulation therapy is observed, anticoagulation is contraindicated or in catheter infection. Anticoagulation should continue for as long as the catheter is in place and for at least 3 months after catheter removal. For massive CVC-associated UEDVT and PE, thrombolytic therapy must be considered.

\section{Recommendation}

The treatment strategy of CVCAT should be the same as recommended in the treatment of DVT of the lower limbs (level of evidence: grade $2 \mathrm{C}$ ).

Treatment of acute PE

The clinical spectrum of PE ranges from an acute lifethreatening event to a silent finding in scheduled CT scans. The strongest predictor for short-term PE-related mortality is hemodynamic status. In patients with hemodynamic instability the short-term mortality rate ranges from 15 to $60 \%$ of cases and acute thrombolytic therapy should be considered in this setting after weighting the PE severity and the risk of bleeding. The use of the catheter or surgical embolectomy may also be considered in patients with massive PE with contraindications to thrombolytic therapy or in those that remain unstable after thrombolysis. However, the vast majority of patients with PE are hemodynamically stable at diagnosis. Anticoagulation with 
LMWH is currently the treatment of choice in patients with normotensive PE even in those with right ventricular dysfunction according to data from recent trials which have failed to demonstrate that the benefits of systemic thrombolysis outweigh the risk of bleeding in this setting. Several risk-stratification tools that include clinical decision rules, cardiac biomarkers or imaging tests have been developed to classify patients with normotensive PE. Of note, since cancer has been found to be an independent predictor of death in series of patients with acute symptomatic PE, general PE prognostic scales include cancer as a predictive variable limiting its use in the cancer population. This fact has led to the development of specific prognostic scales for acute symptomatic cancer-related PE including the POMPE-C tool [27] and a score derived from the Riete registry [28].

\section{Recommendation}

LMWH is the treatment of choice in patients with PE (level of evidence: grade 1A).

\section{Treatment of incidental PE}

It is known that subclinical or asymptomatic PE may be present in up to $50 \%$ of patients with acute DVT. Incidental or unsuspected VTE found during the evaluation of scheduled CT scan evaluations in cancer patients is common, accounting for 2-5\% of all CT scans. Incidental PE currently represents about $50 \%$ of PE burden in cancer patients. Moreover, the incidence of incidental VTE is likely to increase further with the improvements of imaging techniques. Limited data from retrospective and observational cohorts of patients suggest that patients with incidental VTE would have similar outcomes with regard to overall survival and the risk of bleeding and VTE recurrence compared to patients with acute symptomatic events [29]. Unfortunately, there is a lack of evidence from prospective interventional studies to assess the best management of incidental VTE and whether anticoagulation is indicated or beneficial in patients with incidental VTE remains controversial. Expert recommendations suggested treating incidental VTE with standard full-dose anticoagulation therapy similarly to symptomatic events. However, in cases where the diagnosis of VTE is doubtful or questionable such as in cases of isolated subsegmental PE, additional confirming tests such as compression venous ultrasonography or CT scan pulmonary angiography should be performed.

\section{Recommendation}

Anticoagulation therapy is considered the standard treatment of incidental PE (level of evidence: grade 1C).

\section{Long-term treatment of CAT}

The preferred agent for long-term management and secondary VTE prophylaxis (from first 5-10 days up to 3-6 months after the VTE diagnosis) in cancer patients is LMWH. This recommendation is based on several randomized controlled trials [30-33] and a meta-analysis of 7 studies [34] which have provided consistent evidence on improved efficacy of LMWH (dalteparin, enoxaparin and tinzaparin) compared to vitamin $\mathrm{K}$ (VKA) antagonists in this setting (Table 5). Overall, a relative risk reduction of $53 \%$ in the prevention of recurrent VTE has been observed with the use of LMWH compared to VKA with similar rates of major bleeding and overall mortality. A post hoc analysis of CLOT trial [35] showed that treatment with dalteparin was associated with improved overall survival in patients without metastatic disease (probability of death at 12 months: $20 \%$ in the dalteparin group vs. $36 \%$ in the VKA arm, HR 0.50 ; $95 \%$ CI $0.27-0.95$; $p=0.03$ ) compared to AVK treatment. In the largest one of these trials, the CLOT study, dalteparin was administered at a full dose for the first month followed by a $25 \%$ reduction in the treatment dose for the remaining 5 months. This LMWH dose reduction approach can be considered especially in patients with previous history of bleeding or with a higher risk of bleeding. LMWH offers additional advantages compared to VKA in the long-term management of cancerrelated VTE: limited drug interaction and a shorter half-life that facilitates temporary interruption for invasive procedures or thrombocytopenia.

Unfortunately, trials addressed to test the risk/benefit of extended duration of anticoagulation beyond 6 months are not available. Individualized decisions to tailor therapy according to the characteristics and preferences of each patient are challenging in clinical practice. Specific tools aimed to 'predict VTE recurrence' have been developed in recent years which may provide further support to clinicians in the decision to maintain extended anticoagulation beyond 6 months. Four risk assessment models combining clinical and biomarker variables are currently available to predict VTE recurrence, of which only one was specifically designed to predict recurrence in cancer patients known as Ottawa score [36] (Table 6).

\section{Recommendation}

The preferred agent for long-term anticoagulant treatment of VTE in cancer patients is LMWH for at least 6 months (level of evidence: grade 1A). Extended duration of anticoagulation therapy after 6 months should be considered for high-risk patients such as those with active cancer and those receiving chemotherapy. Beyond 6 months, patients should be re-evaluated frequently to assess the risk-benefit 
Table 5 Randomized trials comparing LMWH with AVK for cancer-related VTE secondary prophylaxis

\begin{tabular}{|c|c|c|c|c|c|c|}
\hline $\begin{array}{l}\text { Clinical trial/ } \\
\text { year }\end{array}$ & Study drug & $N$ & $\begin{array}{l}\text { Observation } \\
\text { period }\end{array}$ & $\begin{array}{l}\text { Recurrent VTE } \\
\text { (VKA vs. LMWH) }\end{array}$ & $\begin{array}{l}\text { Major bleeding } \\
\text { (VKA vs. LMWH) }\end{array}$ & $\begin{array}{l}\text { Mortality (VKA vs. } \\
\text { LMWH) }\end{array}$ \\
\hline CLOT 2003 & $\begin{array}{l}\text { Dalteparin } 25 \% \text { LMWH dose } \\
\text { reduction after } 1 \text { month }\end{array}$ & 672 & 6 months & 17 vs. $9 \% ; p=0.02$ & 4 vs. $6 \% ; p=0.27$ & $\begin{array}{c}41 \text { vs. } 39 \% \\
p=0.53\end{array}$ \\
\hline $\begin{array}{l}\text { CANTHANOX } \\
2002\end{array}$ & Enoxaparin full dose once daily & 146 & 3 months & $\begin{array}{l}21.1 \text { vs. } 10.5 \% \\
p=0.09\end{array}$ & 16 vs. $7 \% ; p=0.09$ & $\begin{array}{l}22.7 \text { vs. } 11.3 \% \\
p=0.07\end{array}$ \\
\hline $\begin{array}{l}\text { ONCENOX } \\
2006\end{array}$ & $\begin{array}{l}\text { Enoxaparin } 2 \text { full-dose schemes } \\
\text { (twice and once daily })^{\mathrm{a}}\end{array}$ & 122 & 6 months & $\begin{array}{l}10 \text { vs. } 6.9 \text { vs. } 6.3 . \% \\
p=\mathrm{NS}\end{array}$ & $\begin{array}{l}2.9 \text { vs. } 6.5 \text { vs. } \\
11.1 \% ; p=\mathrm{NS}\end{array}$ & $\begin{array}{l}32.4 \text { vs. } 22.6 \text { vs. } \\
41.7 \% ; p=\mathrm{NS}\end{array}$ \\
\hline LITE 2006 & Tinzaparin full dose & 200 & 3 months & $\begin{array}{r}16 \text { vs, } 7 \% \\
p=0.044\end{array}$ & 7 vs. $7 \% ; p=\mathrm{NS}$ & $\begin{array}{c}19 \text { vs. } 20 \% \\
p=\mathrm{NS}\end{array}$ \\
\hline
\end{tabular}

${ }^{a}$ AVK vs. enoxaparin $1 \mathrm{mg} / \mathrm{KG} / 12 \mathrm{~h}$ and AVK vs. enoxaparin $1.5 \mathrm{mg} / \mathrm{kg} / \mathrm{day}$

Table 6 Risk assessment model for cancer-associated recurrent VTE: the Ottawa score

\begin{tabular}{lc}
\hline Risk factor & Points \\
\hline Female sex & +1 \\
Lung cancer & +1 \\
Breast cancer & -1 \\
TNM stage I & -2 \\
Prior VTE & +1 \\
\hline
\end{tabular}

-3 to 0 points: low VTE recurrence probability $(\leq 4.5 \%$ VTE recurrent risk)

1 to 3 points: high VTE recurrence probability ( $>19 \%$ VTE recurrent risk)

ratio of continuing anticoagulant therapy (level of evidence: grade $2 \mathrm{C}$ ).

\section{Special situations in the management of cancer- associated VTE}

Treatment of recurrent VTE during anticoagulation therapy

The reported rates of recurrent VTE during anticoagulant therapy in clinical trials are $7-10.5 \%$ in patients treated with LMWH (Table 5). Gender, tumor type, TNM staging and prior history of VTE have been found to be risk factors for VTE recurrence in cancer patients. Cancer progression should also be considered in patients with recurrent VTE. Despite the high frequency and relevance of recurrent VTE in clinical practice, there is a lack of evidence to guide its management. An empirical approach for the management of recurrent VTE is proposed (Fig. 1). HIT in patients who were first exposed to LMWH or UFH, non-compliance and sub-therapeutic anticoagulant doses have to be ruled out and adjusted. If recurrent VTE occurs while receiving therapeutic anticoagulation VKA doses, it is recommended VKA be switched to LMWH. In patients who experience VTE recurrence despite therapeutic weight-adjusted LMWH, it is recommended to continue $\mathrm{LMWH}$ at a higher dose starting with an LMWH dose escalation by 20-25\%. If another VTE episode occurs after the first dose escalation, further dose increase or twice-daily dosing of LMWH is considered to be reasonable option. The use of peak anti-activated factor $\mathrm{X}$ (anti-factor Xa) levels may help to estimate further tailor LMWH escalation, although published evidence to support this strategy is lacking. The insertion of an inferior vena cava (IVC) filter in addition to anticoagulation is not currently recommended in preventing recurrent thrombosis. Data on the efficacy and safety of IVC filters in cancer patients are limited to retrospective single-center series and anecdotal reports. Available data from the PREPIC trial shows that IVC filter reduced the risk of PE but increased that of DVT and had no impact on patient survival [37]. Therefore, the use of IVC filters should be considered only in patients who cannot received anticoagulation or recurrent VTE occurs despite adequate anticoagulant therapy management, although evidence from prospective data are not available.

\section{Recommendation}

If recurrent VTE occurs with therapeutic weight-adjusted doses, a dose escalation could be performed (level of evidence: grade $2 \mathrm{C}$ ).

IVC must be considered when anticoagulation is contraindicated or recurrent PE occurs despite adequate anticoagulant management (failure of anticoagulation). It is recommended to associate anticoagulation therapy to IVC, in those cases in which anticoagulation is contraindicated, it should be resumed as soon as possible (level of evidence: grade $2 \mathrm{C}$ ).

\section{Thrombocytopenia}

The optimal dosing of LMWH in the thrombocytopenic patient has not been properly investigated in clinical trials. The recommended approach by expert consensus is to maintain full-dose anticoagulation for platelet count $>50 \times 10^{9} / \mathrm{L}$. For platelet counts between 20 and 
$50 \times 10^{9} / \mathrm{L}$, half-dose or prophylaxis dose of LMWH and close monitoring. And for platelet count $<20 \times 109 / \mathrm{L}$, it is recommended to hold anticoagulation. In the acute period after VTE (first month), the risk of recurrent VTE is higher and platelet transfusion to maintain platelet counts $>50 \times 10^{9}$ should be considered to allow maintaining a full-dose anticoagulant treatment.

Anticoagulation in special situations: obesity, renal impairment and elderly

LMWH must be used with caution in obese and elderly patients and in those with renal insufficiency. Due to their predominantly renal elimination, LMWH accumulation is expected with long-term use in those with creatinine clearance $<30 \mathrm{~mL} / \mathrm{min}$. Obese patients and elderly patients have a lower proportion of lean body mass as a percentage of total body weight. As a result, LMWH dosing based on total body weight could cause supra-therapeutic anticoagulation. LMWH appropriate dosing in patients with severe renal impairment $(\mathrm{CrCl}<30 \mathrm{~mL} / \mathrm{min})$ is uncertain and must be cautiously used with regular monitoring of renal function and anti-Xa levels with dosage adjustment. UFH and AVK therapy are not reliant on renal elimination and are considered to be an alternative approach in this setting for long-term treatment according to expert recommendations if anti-factor $\mathrm{Xa}$ is not available.

Anticoagulation and central nervous system malignancies

VTE is common perioperatively and through the course of brain tumor therapy with an incidence of 20-30\% per year of survival. These patients also have the risk of potentially
Fig. 1 Management of recurrent cancer-associated thrombosis (CAT)

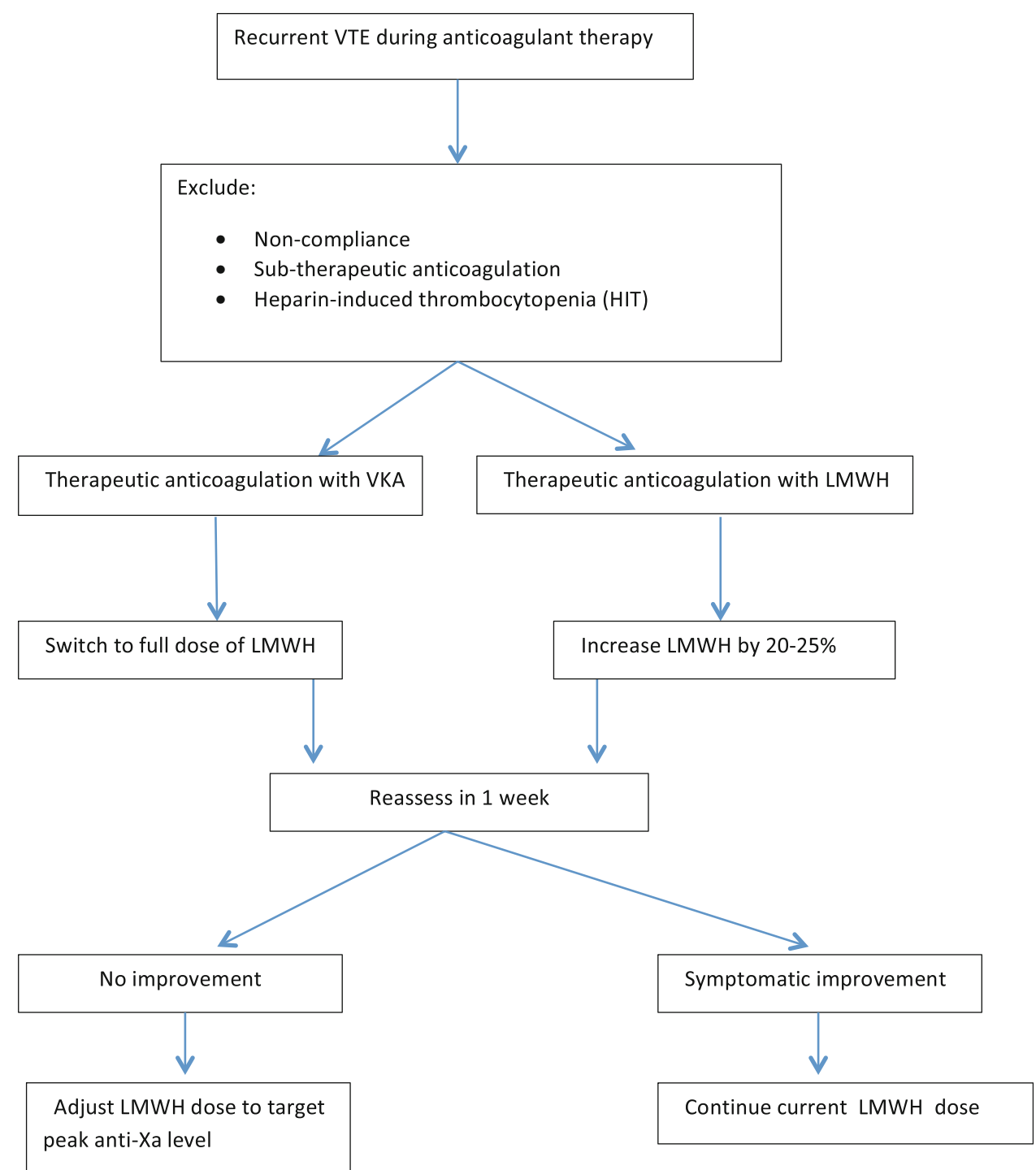


serious and life-threatening intracranial bleeding. No randomized controlled trials exist to evaluate the best management of VTE in patients with primary or metastatic intracranial tumors. Nonetheless, small retrospective studies indicate that anticoagulation can be safely used in this challenging setting and therefore standard anticoagulation is recommended in these patients.

Management of splanchnic vein thrombosis

Splanchnic vein thrombosis (SVT), involving the portal, splenic, mesenteric, or hepatic veins is a common event in cancer patients. Treatment of SVT is a clinical challenge due to heterogeneity of clinical presentations, increased bleeding risk, and lack of evidence from clinical trials. In recent years, different advances in diagnostic imaging techniques have led to an increase in the diagnosis of incidental SVT. Patients with acute, symptomatic SVT with low risk of bleeding should be treated with anticoagulation therapy. For patients with asymptomatic incidentally detected SVT, there is no specific guidance on treatment. It is reasonable to withhold anticoagulation if the patient is truly asymptomatic, especially if radiologic evidence indicates that the thrombus is chronic. Closely monitoring imaging is recommended to detect thrombus progression if anticoagulation is not given.

\section{Recommendation}

Acute symptomatic SVT should be treated with anticoagulant therapy. Treatment of asymptomatic incidentally detected SVT should be individualized in every patient (level of evidence: grade 2C).

\section{Prevention of PTS}

PTS is a frequent complication (20-50\%) within the first 2 years after DVT and is a common cause of morbidity. Clinical manifestations are usually leg pain, edema, swelling and eczematous skin changes which may range from mild complaints to intense pain intervening with daily activities. The only method that has been shown to be potentially effective in the prevention of PTS is the use of graduated compression stockings. Previous small and nonplacebo trials suggest a benefit of elastic compression stockings (ECS) to prevent PTS with an overall reduction of $50 \%$ in severe PTS. A recent study published in 2014 (SOX trial) [38] randomized patients to ECS used for 2 years or placebo after a first proximal DVT. The incidence of PTS was $14.2 \%$ in the experimental arm vs. $12.7 \%$ in the placebo group (HR 1.13, $95 \%$ CI 0.73-1.76; $p=0.58$ ). The findings of the SOX trial do not support routine wearing of ECS after DVT for the prevention of PTS.

\section{Recommendation}

ECS is not recommended routinely to prevent PTS (level of evidence: grade $1 \mathrm{~B}$ ).

VTE: Antiangiogenic therapy/anti-epidermal growth factor receptor (EFGR) therapy

Venous or arterial thromboembolism and bleeding are adverse events linked to angiogenesis inhibitors. Combination treatment with bevacizumab and chemotherapy compared with chemotherapy alone was associated with a modest but significant twofold increased risk of arterial thromboembolic disease (ATD), but the impact on the risk of VTE remains controversial [39, 40]. Development of ATD with bevacizumab treatment was associated with a prior arterial thromboembolic event in patients older than 65 years. The prophylactic use of acetylsalicylic acid is controversial. The start of treatment with bevacizumab after an ATD must be individualized, but the minimum interval recommended is 6 months. If an ATD takes place during treatment with bevacizumab, its use must be stopped permanently because the safety of resuming bevacizumab has not been studied. In patients who develop VTE during bevacizumab treatment, the minimum safety interval recommended to resume bevacizumab is 2 weeks with stable dose of anticoagulant treatment. If there is a grade 4 VTE episode during treatment with bevacizumab, its use must be permanently stopped. Recommendations regarding aflibercept (an anti-VEGF recombinant fusion protein) are similar to those with bevacizumab.

VEGF tyrosine kinase inhibitors (TKI) are used in multiple cancers. In a meta-analysis evaluating the risk of ATD associated with sunitinib and sorafenib, a significant threefold increase was observed [41]. These results may be related to the higher time exposure to sunitinib and sorafenib in the trials as confounding factor.

A meta-analysis that explored the risk of VTE with antiEGFR drugs (either monoclonal antibodies-MoAbs- or TKIs) showed that anti-EFGR therapy increased by $32 \%$ the risk of VTEs, but not of ATEs. This thrombotic risk is increased with cetuximab and panitumumab but not with gefitinib and erlotinib. The differences in the results between MoAbs and oral TKIs are still unknown, but the association of cetuximab and panitumumab with other cytotoxic agents probably matters [42].

Anticoagulation in the absence of VTE to improve survival in cancer patients

The mechanism by which anticoagulation might provide a survival benefit beyond the prevention of VTE is unknown. Several clinical trials have tested anticoagulant therapy in 
cancer patients without VTE with survival as primary end point with inconclusive results [43-46]. The survival benefit may be dependent on the tumor and the extent of disease, being larger with localized disease and small-cell lung cancer.

\section{Recommendation}

Currently anticoagulant therapy in cancer patients without VTE with the intention to improve survival cannot be recommended (level of evidence: grade 1B).

New oral anticoagulants and VTE in cancer patients

There are three (NOACs) currently marketed in Spain, dabigatran etexilate (direct thrombin inhibitor), rivaroxaban and apixaban (factor Xa inhibitors). NOACs have been studied in large randomized clinical trials for acute VTE treatment and for VTE prophylaxis. In these trials, the number of patients with active cancer enrolled was small. Due to the paucity of data in the oncology subgroup, the results of these trials cannot be generalized to cancer patients, and additional information is needed about the efficacy and safety of NOACs in this population. There is an additional concern about the drug interactions between NOACs and either chemotherapy or biological treatments.

\section{Recommendation}

NOACS are not recommended for the treatment of VTE in cancer patients (level of evidence: grade 1B).

\section{Anti-Xa monitoring}

The determination of anti-Xa in blood is the method of choice for monitoring the therapeutic range of LMWH. Anti-Xa monitoring is not routinely recommended in LMWH treatment. There is only one randomized trial that compares adjusted vs. fixed doses of LMWH in the treatment of DVT. Treatment efficacy and hemorrhagic complications did not differ between the two groups [47]. In special populations like obese, renally impaired, elderly, thrombocytopenic or patients with high risk of bleeding anti-Xa is currently recommended.

\section{Recommendation}

Anti-Xa monitoring is not routinely recommended in LMWH treatment (level of evidence: grade 1B).

Conflict of interest Dr. Andres J. Muñoz Martin: "I declare to have received a research funding from Leo Pharma at the time of the presentation of the Clinical Guideline, to have a consultant or advisory role at Sanofi and Laboratorios Rovi. These activities, such as the research funding have no connection, nor have influenced the content of the present Clinical Guide. Therefore, I declare no conflict of interest." The rest of the authors of this Clinical Guide declare no conflicts of interests.

Open Access This article is distributed under the terms of the Creative Commons Attribution License which permits any use, distribution, and reproduction in any medium, provided the original author(s) and the source are credited.

\section{References}

1. Epstein AS, Soff GA, Capanu M, Crosbie C, Shah MA, Kelsen DP, et al. Analysis of incidence and clinical outcomes in patients with thromboembolic events and invasive exocrine pancreatic cancer. Cancer. 2012;118:3053-61.

2. Sørensen HT, Mellemkjaer L, Olsen JH, Baron JA. Prognosis of cancers associated with venous thromboembolism. N Engl J Med. 2000;343:1846-50.

3. Guyatt GH, Oxman AD, Vist GE, Kunz R, Falck-Ytter Y, Alonso-Coello P et al. GRADE: an emerging consensus on rating quality of evidence and strength of recommendations. BMJ. 2008;336:924-6.

4. Guyatt GH, Oxman AD, Kunz R, Falck-Ytter Y, Vist GE, Liberati A et al. Rating quality of evidence of and strength of recommendations. BMJ. 2008;336:1049-51.

5. Cohen AT, Davidson BL, Gallus AS, Lassen MR, Prins MH, Tomkowski W et al. Efficacy and safety of fondaparinux for the prevention of venous thromboembolism in older acute medical patients: randomized placebo controlled trial. BMJ. 2006:332:325-9.

6. Samama MM, Cohen AT, Darmon JY, Desjardins L, Eldor A, Janbon C, et al. A comparison of enoxaparin with placebo for the prevention of venous thromboembolism in acutely ill medical patients. Prophylaxis in Medical Patients with Enoxaparin Study Group. N Engl J Med. 1999;341:793-800.

7. Leizorovicz A, Cohen AT, Turpie AG, Olsson CG, Vaitkus PT, Goldhaber SZ, et al. Randomized, placebo-controlled trial of dalteparin for the prevention of venous thrombo-embolism in acutely ill medical patients. Circulation. 2004;110:874-9.

8. Carrier M, Khorana AA, Moretto P, Le Gal G, Karp R, Zwicker JI. Lack of evidence to support thromboprophylaxis in hospitalized medical patients with cancer. Am J Med. 2014;127:82-6.

9. Agnelli G, Bolis G, Capussotti L, Scarpa RM, Tonelli F, Bonizzoni E, et al. A clinical outcome-based prospective study on venous thromboembolism after cancer surgery: the @ RISTOS project. Ann Surg. 2006;243:89-95.

10. Rasmussen MS, Jorgensen LN, Wille-Jørgensen P. Prolonged thromboprophylaxis with low molecular weight heparin for abdominal or pelvic surgery. Cochrane Database Syst Rev. 2009;1:CD004318.

11. Sakon M, Kobayashi T, Shimazui T. Efficacy and safety of enoxaparin in Japanese patients undergoing curative abdominal or pelvic cancer surgery: results from a multicenter, randomized, open-label study. Thromb Res. 2010;125:e65-70.

12. Agnelli G, Gussoni G, Bianchini C, Verso M, Mandalà M, Cavanna L, et al Nadroparin for the prevention of thromboembolic events in ambulatory patients with metastatic or locally advanced solid cancer receiving chemotherapy: A randomized, placebo-controlled, double-blind study. Lancet Oncol. 2009;10:943-9.

13. Agnelli G, George DJ, Kakkar AK, Fisher W, Lassen MR, Mismetti P, et al. Semuloparin for thromboprophylaxis in patients receiving chemotherapy for cancer. N Engl J Med. 2012;366:601-9.

14. Riess H, Pelzer U, Deutschinoff G, Opitz B, Stauch M, Reitzig P, et al. A prospective, randomized trial of chemo- therapy with or without the low molecular weight heparin (LMWH) enoxaparin in patients (pts) with advanced pancreatic cancer (APC): results of the CONKO 004 trial (abstract LBA4506). J Clin Oncol 2009;27:Suppl:18S. abstract.

15. Maraveyas A, Waters J, Roy R, Fyfe D, Propper D, Lofts F, et al. Gemcitabine versus gemcitabine plus dalteparin thromboprophylaxis in pancreatic cancer. Eur J Cancer. 2012;48:1283-92.

16. Akl EA, Gunukula S, Barba M, Yosuico VE, van Doormaal FF, Kuipers S, et al. Parenteral anticoagulation in patients with cancer who have no therapeutic or prophylactic indication for anticoagulation. Cochrane Database Syst Rev. 2011;4:CD006652

17. Di Nisio M, Porreca E, Ferrante N, Otten HM, Cuccurullo F, Rutjes AW Primary prophylaxis for venous thromboembolism in ambulatory cancer patients receiving chemotherapy. Cochrane Database Syst Rev. 2012;2:CD008500.

18. Akl EA, Schünemann HJ. Routine heparin for patients with cancer? One answer, more questions. N Engl J Med. 2012;366(7):661-2. 
19. Palumbo A, Cavo M, Bringhen S, Zamagni E, Romano A, Patriarca F, et al. Aspirin, warfarin, or enoxaparin thromboprophylaxis in patients with multiple myeloma treated with thalidomide: a phase III, open-label, randomized trial. J Clin Oncol. 2011;29(8):986-93.

20. Larocca A, Cavallo F, Bringhen S, DiRaimondo F, Falanga A, Evangelista A, et al. Aspirin or enoxaparin thromboprophylaxis for patients with newly diagnosed multiple myeloma treated with lenalidomide. Blood. 2012;119:933-9.

21. Khorana AA, Kuderer NM, Culakova E, Lyman GH, Francis CW. Development and validation of a predictive model for chemotherapy-associated thrombosis. Blood. 2008;111:4902-7.

22. Saber W, Moua T, Williams EC, Verso M, Agnelli G, Couban S, et al. Risk factors of catheter-related thrombosis (CRT) in cancer patients: a patient-level data (IPD) meta-analysis of clinical trials and prospective studies. J Thromb Haemost. 2011;9:312-9.

23. Prandoni P, Lensing AW, Piccioli A, Bernardi E, Simioni P, Girolami B, et al. Recurrent venous thromboembolism and bleeding complications during anticoagulant treatment in patients with cancer and venous thrombosis. Blood. 2002;100:3484-8.

24. Akl EA, Vasireddi SR, Gunukula S, Beard M, Sperati F, Terrenato I, et al. Anticoagulation for the initial treatment of venous thromboembolism in patients with cancer. Cochrane Database Syst Rev. 2011;15(6):CD006649.

25. Saber W, Moua T, Williams EC, Verso M, Agnelli G, Couban S, et al. Risk factors for catheter-related thrombosis (CRT) in cancer patients: a patient-level data (IPD) meta-analysis of clinical trials and prospective studies. J Thromb Haemost. 2011;9:312-9.

26. Kovacs MJ, Kahn SR, Rodger M, Anderson DR, Andreou R, Mangel JE, et al. A pilot study of central venous catheter survival in cancer patients using lowmolecular-weight heparin (dalteparin) and warfarin without catheter removal for the treatment of upper extremity deep vein thrombosis (The Catheter Study). J Thromb Haemost. 2007;5:1650-3.

27. Kline JA, Roy PM, Than MP, Hernandez J, Courtney DM, Jones AE, et al. Derivation and validation of a multivariate model to predict mortality from pulmonary embolism with cancer; the POMPE-C tool. Thromb Res. 2012;129(5):e194-9.

28. Den Exter PL, Gomez V, Jimenez D, Trujillo-Santos J, Muriel A, Huisman MV, et al. A clinical prognostic model for the identification of low-risk patients with acute symptomatic pulmonary embolism and active cancer. Chest. 2013;143(1):138-45

29. denExter PL, Hooijer J, Dekkers OM, Huisman MV. Risk of recurrent venous thromboembolism and mortality in patients with cancer incidentally diagnosed with pulmonary embolism: a comparison with symptomatic patients. J Clin Oncol. 2011;29:2405-9.

30. Lee AY, Levine MN, Baker RI, Bowden C, Kakkar AK, Prins M, et al. Lowmolecular-weight heparin versus a coumarin for the prevention of recurrent venous thromboembo-lism in patients with cancer. $N$ Engl $J$ Med. 2003;349:146-53.

31. Deitcher SR, Kessler CM, Merli G, Rigas JR, Lyons RM, Fareed J et al. Secondary prevention of venous thromboembolic events in patients with active cancer: enoxaparin alone versus initial enoxaparin followed by warfarin for a 180-day period. Clin Appl Thromb Hemost. 2006;12:389-96.

32. Meyer G, Marjanovic Z, Valcke J, Lorcerie B, Gruel Y, Solal-Celigny P, et al. Comparison of low-molecular-weight heparin and warfarin for the secondary prevention of venous thromboembolism in patients with cancer: a randomized controlled study. Arch Intern Med. 2002;162:1729-35.
33. Hull RD, Pineo GF, Brant RF, Mah AF, Burke N, Dear R et al. Long-term lowmolecular-weight-heparin versus usual care in proximal-vein thrombosis patients with cancer. Am J Med. 2006;119:1062-72.

34. Akl EA, Labedi N, Barba M, Terrenato I, Sperati F, Muti P, et al. Anticoagulation for the long-term treatment of venous thromboembolism in patients with cancer. Cochrane Database Syst Rev. 2011;6:CD006650.

35. Lee AY, Rickles FR, Julian JA, Gent M, Baker RI, Bowden C, et al. Randomized comparison of low molecular weight heparin and coumarin derivatives on the survival of patients with cancer and venous thromboembolism. J Clin Oncol. 2005;23:2123-9.

36. Louzada ML, Carrier M, Lazo Langner A, Dao V, Kovacs MJ, Ramsay TO et al. Development of a clinical prediction rule for risk stratification of recurrent venous thromboembolism in patients with cancer- associated venous thromboembolism. Circulation. 2012;126:448-54.

37. PREPIC Study Group. Eight-year follow-up of patients with permanent vena cava filters in the prevention of pulmonary embolism: the PREPIC (Prevention du Risque d'Embolie Pulmonaire par Interruption Cave) randomized study. Circulation. 2005;112:416-22.

38. Kahn SR, Shapiro S, Wells PS, Rodger MA, Kovacs MJ, Anderson DR, et al. Compression stockings to prevent post-thrombotic syndrome: a randomized placebo-controlled trial. Lancet. 2014;383:880-8.

39. Hurwitz HI, Saltz LB, Van Cutsem E, Cassidy J, Wiedemann J, Sirzén F, et al Venous thromboembolic events with chemotherapy plus bevacizumab: a pooled analysis of patients in randomized phase II and III studies. J Clin Oncol 2011;29(13):1757-64.

40. Hurwitz HI, Tebbutt NC, Kabbinavar F, Giantonio BJ, Guan ZZ, Mitchell L, et al. Efficacy and safety of bevacizumab in metastatic colorectal cancer: pooled analysis from seven randomized controlled trials. Oncologist. 2013;18(9):1004-12.

41. Choueiri TK, Schutz FAB, Je Y, Rosemberg JE, Bellmunt J. Risk of arterial thromboembolic events with sunitinib and sorafenib: a systematic review and meta-analysis of clinical trials. J Clin Oncol. 2010;28:2280-5.

42. Petrelli F, Cabiddu M, Borgonovo K, Barni S. Risk of venous and arterial thromboembolic events associated with anti-EGFR agents: a meta-analysis of randomized clinical trials. Ann Oncol. 2012;23(7):1672-9.

43. Kakkar AK, Levine MN, Kadziola Z, Lemoine NR, Low V, Patel HK, et al. Low molecular weight heparin, therapy with dalteparin, and survival in advanced cancer: the fragmin advanced malignancy outcome study (FAMOUS). J Clin Oncol. 2004;22(10):1944-8.

44. Van Doormaal FF, Di Nisio M, Otten HM, Richel DJ, Prins M, Buller HR, et al. Randomized trial of the effect of the low molecular weight heparin nadroparin on survival in patients with cancer. J Clin Oncol. 2011;29:2071-6.

45. Klerk CP, Smorenburg SM, Otten HM, Lensing AW, Prins MH, Piovella F, et al. The effect of low molecular weight heparin on survival in patients with advanced malignancy. J Clin Oncol. 2005;23:2130-5.

46. Lecumberri R, López Vivanco G, Font A, González Billalabeitia E, Gúrpide A, Gómez Codina J, et al. Adjuvant therapy with bemiparin in patients with limited-stage small cell lung cancer: results from the ABEL study. Thromb Res. 2013;132:666-70.

47. Alhenc-Gelas M, Jestin-Le Guernic C, Vitoux JF, Kher A, Aiach M, Fiessinger $\mathrm{JN}$. Adjusted versus fixed doses of the low-molecular-weight heparin fragmin in the treatment of deep vein thrombosis. Fragmin-Study Group. Thromb Haemost. 1994;71:698-702. 